\title{
Eficiencia energética de fachadas ventiladas con baldosas cerámicas reflectantes al infrarrojo cercano
}

\section{Energy efficiency of ventilated façades with near infrared range reflective ceramic tiles}

G. Silva $^{(*)}$, M. A. Bengochea ${ }^{(* *)}$, L. Guaita ${ }^{(* *)}$, C. Segarra ${ }^{(*)}$, J. Corrales $^{(*)}$

\section{RESUMEN}

La creciente concienciación social respecto a la construcción sostenible y el ahorro energético en edificios está conduciendo a prescriptores y usuarios finales a tomar en consideración nuevas soluciones constructivas. Sin embargo, su introducción en el mercado es lenta y difícil, debido tanto a las limitaciones de las herramientas reconocidas de simulación térmica, que no permiten efectuar estimaciones integrando sistemas innovadores, como a la dificultad para validar su eficiencia en edificios reales previamente a su comercialización. En el presente trabajo se analiza la eficiencia energética de una fachada ventilada resuelta con baldosas cerámicas reflectantes al infrarrojo cercano, mediante la integración en el programa EnergyPlus de un modelo matemático que ha sido validado en el edificio experimental CIES Living Lab de Castellón.

Palabras clave: cerámica reflectante; fachada ventilada; consumo energético; simulación.

\section{ABSTRACT}

The growing social awareness with regard to sustainable construction and energy efficiency in buildings is leading specifications writers and end users to take into account new construction solutions. However, the introduction of these construction solutions into the market is slow and difficult owing to the limitations of the recognised thermal simulation tools, which do not allow estimations to be made when integrating innovative systems, and to the difficulty of validating their efficiency in actual buildings before marketing them. The present study analyses the energy efficiency of a ventilated façade made up of near-infrared reflective ceramic tiles, by integrating a mathematical model validated in the CIES Living Lab experimental building in Castellón into the EnergyPlus program.

Keywords: reflective ceramic tiles; ventilated façade; energy consumption; modelling.

(*) Instituto de Tecnología Cerámica (ITC-AICE). Universitat Jaume I. Castellón (España)

(**) Keraben Systems. Grupo KERABEN.

Persona de contacto/Corresponding author: gonzalo.silva@itc.uji.es (G. Silva)

Cómo citar este artículo/Citation: Silva, G., Bengochea, M. A., Guaita, L., Segarra, C., Corrales, J. (2016). Eficiencia energética de fachadas ventiladas con baldosas cerámicas reflectantes al infrarrojo cercano. Informes de la Construcción, 68(544): e160, doi: http:// dx.doi.org/10.3989/ic.15.163.m15.

Copyright: (C) 2016 CSIC. Licencia / License: Salvo indicación contraria, todos los contenidos de la edición electrónica de Informes de la Construcción se distribuyen bajo una licencia de uso y distribución Creative Commons Attribution License (CC BY) Spain 3.o. 


\section{INTRODUCCIÓN}

La transmisión de energía a través de los cerramientos opacos de una vivienda puede suponer alrededor del $35 \%$ del consumo energético para su climatización. En las zonas geográficas soleadas la energía procedente de la radiación solar se absorbe en las superficies exteriores aumentando su temperatura, especialmente en aquellas de color más oscuro que debido a su menor reflectancia pueden llegar a alcanzar valores cercanos a los $70^{\circ} \mathrm{C}$. Al aumentar su temperatura, las superficies emiten parte de dicha energía en forma de radiación infrarroja de onda larga, afectando a las superficies colindantes y contribuyendo a favorecer el fenómeno denominado como «isla de calor urbana» (1), (2).

El aumento de temperatura en la envolvente, generado tanto por la radiación solar directa como por la emitida por los edificios y superficies cercanas, se transfiere hacia el interior de los edificios por conducción, y por lo tanto aumenta el consumo energético necesario para refrigeración. Por ello, en climas cálidos y soleados se tiende a evitar la utilización de cerramientos opacos de colores oscuros, lo que limita las posibilidades de diseño arquitectónico de la envolvente.

Existen diferentes soluciones en el mercado para reducir las ganancias térmicas producidas por la radiación solar, entre las que destacan los cerramientos ventilados y los recubrimientos reflectantes al infrarrojo. Estos últimos, principalmente pinturas que se utilizan para rehabilitar cubiertas con la denominación genérica Cool roofs, presentan ciertas limitaciones en cuanto a su durabilidad debido a su naturaleza mayoritariamente orgánica.

En el marco del proyecto europeo COOL-COVERINGS (FP7 CA 260132) se desarrollaron superficies cerámicas reflectantes al infrarrojo cercano, que debido a su alta durabilidad permiten nuevas aplicaciones en cerramientos verticales. En este trabajo se analiza la eficiencia energética de un sistema constructivo que combina un cerramiento de fachada ventilada con estas nuevas piezas cerámicas reflectantes. Esta solución constructiva se ha evaluado en condiciones reales de uso en el edificio experimental CIES Living Lab, en el marco del programa Building Technologies Accelerator (BTA) de la plataforma Climate-KIC.

\section{FACHADA VENTILADA REFLECTANTE AL INFRARROJO CERCANO}

\subsection{Fachada ventilada cerámica}

La fachada ventilada es un cerramiento multi-estrato que se caracteriza fundamentalmente por incluir una cámara ventilada, limitada por dos hojas: una interior, encargada de aportar el aislamiento térmico y la estanqueidad, y otra hoja exterior, cuya misión principal es formar dicha cámara de aire, garantizando una ventilación continuada a lo largo de toda la superficie de la fachada. La energía procedente de la radiación solar que absorbe la hoja exterior produce el calentamiento del aire en el interior de la cámara, que al reducir su densidad genera un movimiento ascendente por convección natural que disipa la energía acumulada evacuando el aire caliente hacia el exterior (Figura 1). Asimismo, parte de dicha energía es reflejada por la hoja externa, y en su conjunto ambos mecanismos reducen la temperatura de la hoja interior del muro soporte. Por ello el sistema constructivo de fachada ventilada con baldosas cerámicas permite limitar las ganan-

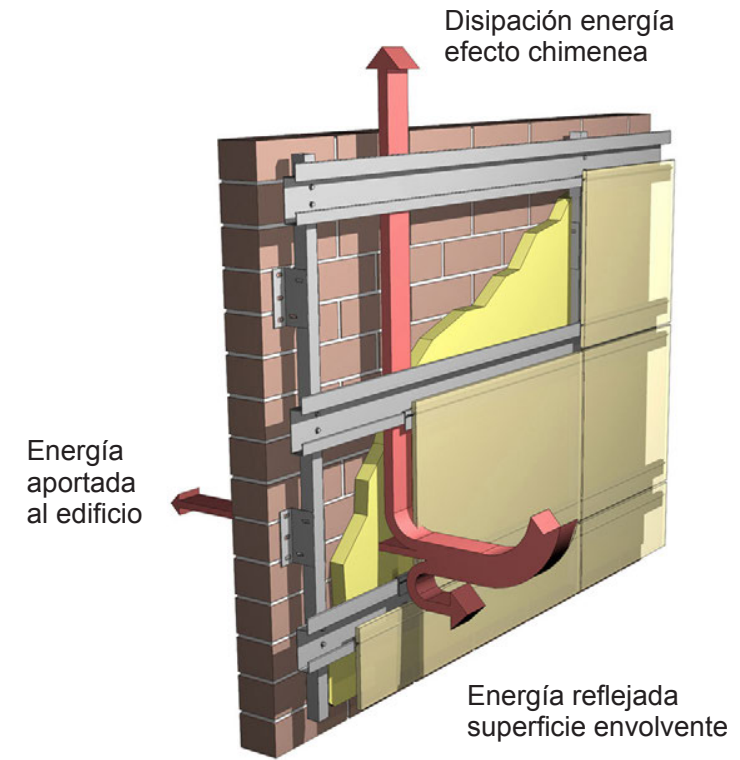

Figura 1. Esquema flujos de energía en un sistema constructivo de fachada ventilada cerámica.

cias térmicas a través del cerramiento, y con ello reducir la demanda de refrigeración del edificio.

Estudios teóricos previos (3), (4) y de monitorización en edificios reales con fachada ventilada (5) confirman las posibilidades de los cerramientos ventilados como sistemas pasivos que reducen significativamente el consumo energético para refrigeración. La fachada ventilada es especialmente adecuada en zonas geográficas con alta incidencia solar, ya que limita las ganancias térmicas desde el exterior, pero también resulta efectiva en climas templados como sistema de rehabilitación para mejorar la transmitancia de los cerramientos, al incorporar una capa de aislamiento por el exterior que elimina los puentes térmicos del edificio.

Más allá de su contribución desde el punto de vista energético, esta solución constructiva conlleva otras ventajas como:

- Incrementa el aislamiento acústico, gracias al aislamiento y a la capa externa de recubrimiento.

- Protege la estructura de albañilería contra la acción directa de los agentes atmosféricos y posibilita ocultar instalaciones, etc.

- Prolonga la vida útil del aislante, que se mantiene seco y sin degradarse gracias a la protección del recubrimiento y a la ventilación.

- Permite actuaciones de rehabilitación por el exterior más rápidas y sin limitar el uso normal de las instalaciones.

- No requiere de mantenimiento periódico, pero en caso necesario permite intervenir individualmente sobre cada una de las piezas.

Asimismo, permite una gran flexibilidad en el diseño de la envolvente, especialmente necesaria en grandes proyectos en los que es un requisito implícito la diferenciación y combinación de elementos, colores, etc.

\subsection{Piezas cerámicas reflectantes en el rango cercano al infrarrojo}

Si analizamos el espectro de radiación solar incidente podemos comprobar que un $3 \%$ de su energía se encuentra en el 
rango ultravioleta (UV, 15 a $400 \mathrm{~nm}$ ), un $46 \%$ en el espectro visible (VIS, 400 a $700 \mathrm{~nm}$ ) y un $52 \%$ en el rango cercano al infrarrojo (NIR, 700 a $2.500 \mathrm{~nm}$ ), siendo este último el que contribuye en mayor medida al calentamiento de las superficies.

Los materiales oscuros, con baja reflectancia en el VIS, absorben más energía y, por tanto, alcanzan temperaturas más elevadas que los materiales claros. Cuando en el diseño de la envolvente de un edificio se requiere de la utilización de materiales oscuros, pero debido a las condiciones climáticas debe limitarse la demanda de refrigeración del edificio, la solución más sencilla es la utilización de materiales con alta reflectancia en el NIR, ya que la contribución energética en este rango de longitudes de onda es muy significativa.

En el desarrollo del proyecto COOL-COVERINGS (FP72010-NMP-ENV-ENERGY-ICT-EeB 260132), que fue coordinado por Keraben Grupo (6), se abordó el desarrollo de materiales con alta reflectancia en el NIR para el recubrimiento de fachadas y cubiertas. La investigación se orientó hacia tres gamas de producto (membranas asfálticas, pinturas y baldosas cerámicas), por ser las soluciones más utilizadas y como mayores posibilidades de integrar recubrimientos superficiales.

En el caso de las baldosas cerámicas se estudiaron diferentes modificaciones de la formulación de la capa de esmalte aplicada sobre la pieza. Para ello se diseñaron esmaltes con diferentes contenidos en pigmentos inorgánicos negros y marrones. Éstos se aplicaron con distintos espesores sobre diferentes soportes, cociendo las piezas esmaltadas a $1.180^{\circ} \mathrm{C}$. Estas piezas cerámicas «COOL» se caracterizaron determinando la reflectancia solar y la emisividad térmica.
Modificando la composición y microestructura del vidriado se consiguió incrementar la reflectancia solar desde un valor inicial de 0,12, para una pieza negra convencional, a un valor de 0,31, para un negro «frío». En la Figura 2 se muestran las curvas de reflectancia de dos baldosas del mismo color oscuro: una convencional y otra fría. Como puede observarse, la reflectancia en el visible de ambas piezas es similar, pero en el NIR la pieza «COOL» es mucho más reflectante que la convencional.

Durante el desarrollo del proyecto también se realizó un estudio comparativo de la variación de la reflectancia espectral y del color con la exposición ambiental, durante varios meses, de las piezas cerámicas reflectantes y de otros tipos de recubrimientos reflectantes existentes en el mercado, concretamente pinturas (7), (8). Aunque las pinturas reflectantes sí manifestaron variaciones con el tiempo, tanto la reflectancia espectral como el color piezas cerámicas reflectantes permaneció invariable durante el tiempo de exposición, lo que garantiza la durabilidad de sus prestaciones térmicas.

Para el desarrollo del estudio la empresa Keraben Grupo fabricó un lote de piezas cerámicas reflectantes (COOL) y otro lote de piezas cerámicas convencionales (STD) del mismo color. Al objeto de verificar su capacidad reflectante, estas piezas se evaluaron inicialmente en el recinto instrumentado para exposición ambiental de cerramientos, ubicado en la azotea de ITC-AICE en Castellón.

En la Figura 3 se presenta la diferencia entre las temperaturas máximas diarias de la piezas STD y COOL, que manifiesta una tendencia creciente respecto a la radiación solar, con una dispersión significativa asociada a las pérdidas por convección que dependen de la velocidad del viento. En los días soleados

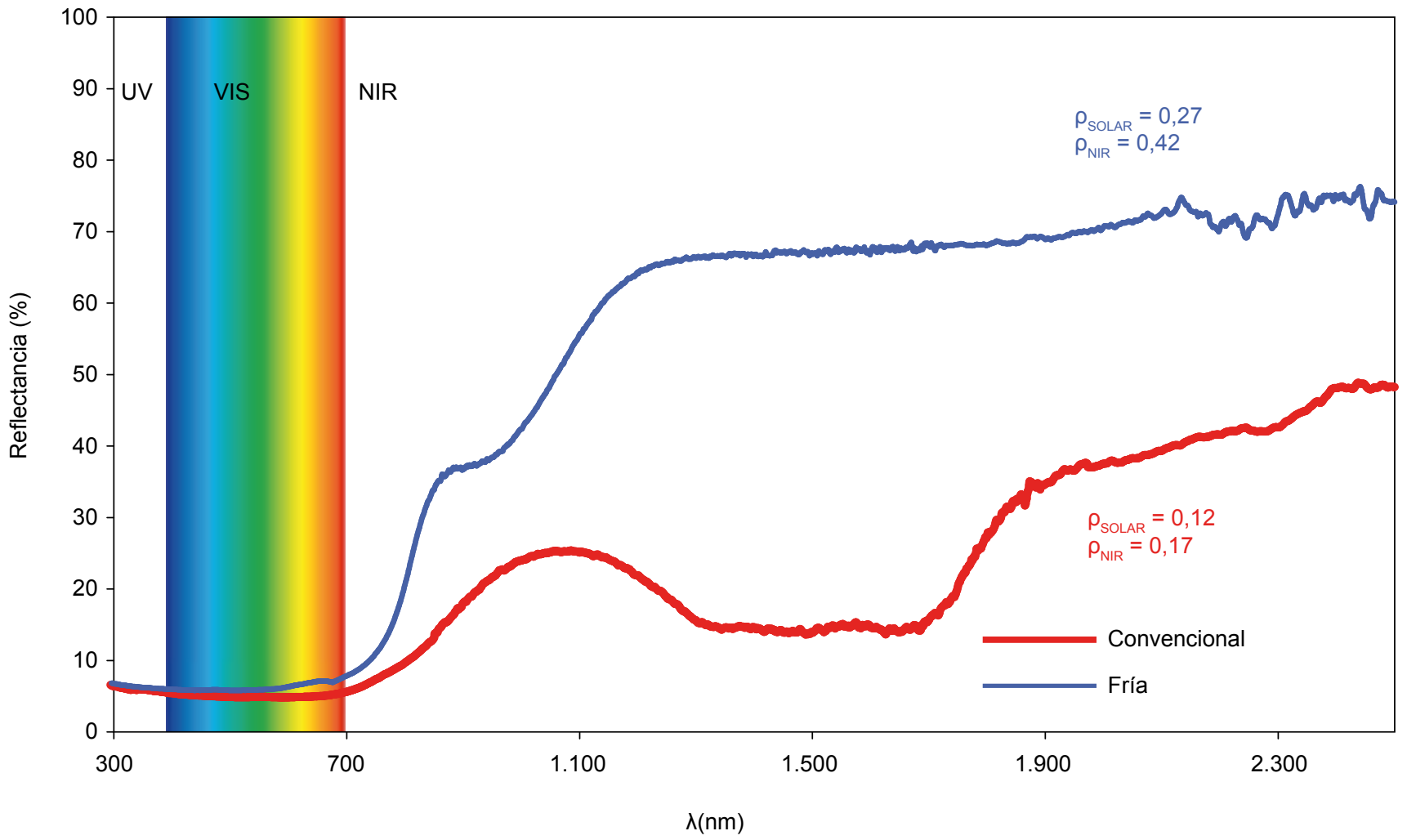

Figura 2. Reflectancia espectral de una baldosa oscura convencional y de una baldosa fría, de la misma tonalidad. 


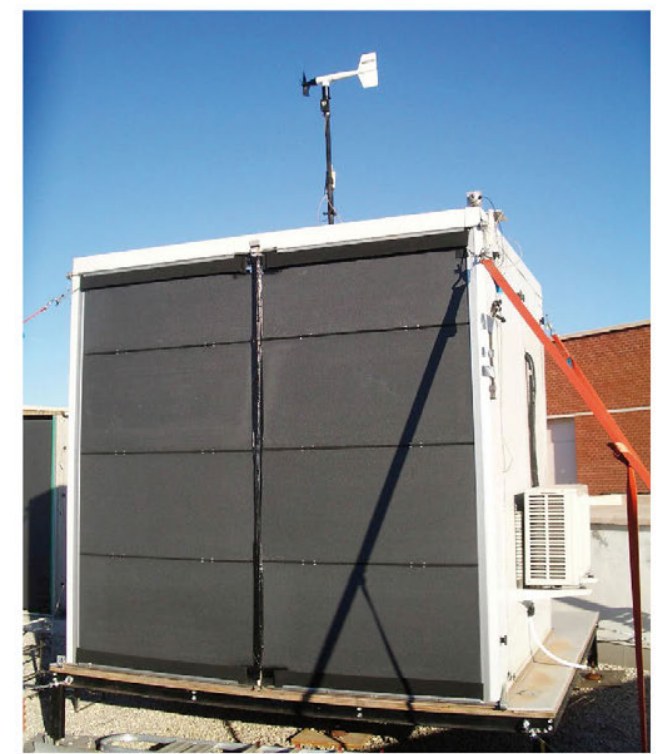

Figura 3. Recinto instrumentado para exposición ambiental de cerramientos (izquierda). Resultados comparativos de temperatura máxima en piezas (derecha). con velocidades bajas de viento, la diferencia de temperatura máxima entre las piezas reflectantes y las convencionales del mismo color puede alcanzar alrededor de $6^{\circ} \mathrm{C}$.

\section{INSTALACIÓN Y MONITORIZACIÓN FACHADA VENTILADA REFLECTANTE EN EDIFICIO CIES LIVING LAB}

La evaluación experimental en condiciones reales de utilización del sistema de fachada ventilada reflectante NIR se ha efectuado en el edificio experimental CIES Living Lab de Castellón. Este estudio se enmarca en el programa Building Technologies Accelerator (BTA) de la plataforma europea Climate-KIC, cuyo objetivo es acelerar la implementación en el mercado de soluciones constructivas innovadoras que contribuyan a reducir las emisiones de $\mathrm{CO}_{2}$ y con ello contribuir a alcanzar los objetivos Europa 2020. Entre otras actuaciones, el programa BTA ha constituido una red de 6 edificios-laboratorio en cuatro países europeos, para facilitar la evaluación de las soluciones constructivas que se están realizando en los diferentes proyectos que desarrolla, habiéndose destinado el edificio CIES a la evaluación de tecnologías en climas templados.

Para la evaluación energética de la fachada ventilada reflectante en este edificio experimental se sustituyó la cubierta ligera original en la fachada Sur-Oeste $\left(210^{\circ}\right)$ por el sistema de fachada ventilada reflectante (Figura 4, izquierda). Se instalaron un total de cuatro canales de fachada ventilada, dos de ellos con piezas cerámicas convencionales (STD) y otros dos con piezas reflectantes (COOL), todas ellas del mismo color.

Cada canal se ha instrumentado con diferentes sensores (Figura 4, derecha) para registrar la evolución de las variables características del sistema de fachada ventilada y las condiciones ambientales:

- Baldosa cerámica: temperatura en la cara interior de cada pieza.

- Canal ventilado: temperatura y velocidad del aire en su interior.
- Muro soporte: temperatura en cara exterior e interior a varias alturas. Sensores de flujo de calor situados en su cara exterior para la medida de la conducción a través del muro.

- Recinto interior: temperatura del aire interior a diferentes alturas.

- Condiciones ambientales: temperatura ambiente, sendos piranómetros para medir la radiación solar total (Gs) y difusa (Gs,dif), anemómetro para determinar la velocidad y la dirección del viento.

En la Figura 5 se muestra un esquema de la localización de elementos de medida en cada una de las dos zonas de la fachada STD y COOL, que incluyen termopares tipo T, referenciados como T, para el seguimiento de las temperaturas de la cara interior de la pieza cerámica, el aire en el canal, las caras exterior e interior del muro soporte y las temperaturas en el interior del recinto. Asimismo, se utilizaron sensores de velocidad OMRON D6F-Wo1A1 (V) para evaluar la velocidad de circulación del aire en la cámara en el rango de o a $1 \mathrm{~m} / \mathrm{s}$, y medidores del flujo de calor (F) Hukseflux HFPo1 para determinar la transferencia de energía térmica a través del muro. Cada una de las fachadas se ha instrumentado a dos alturas sobre la misma vertical con objeto de evaluar las posibles diferencias entre ambas posiciones.

Una vez finalizada la instalación en el edificio CIES en octubre de 2014, se inició la monitorización de estas variables, con una frecuencia de registros de 1 minuto, y durante un periodo anual completo. En las Figura 6 y Figura 7 se muestra un ejemplo de los datos experimentales obtenidos a lo largo de un día completo en uno de los canales ventilados. Al objeto de favorecer la resolución en la comparación de los resultados experimentales respecto a los obtenidos mediante la simulación, se decidió no utilizar el sistema de climatización y permitir que la temperatura interior alcanzara valores elevados (superiores a $30^{\circ} \mathrm{C}$ en verano). La información obtenida a lo largo de este periodo se ha utilizado para validar el modelo matemático desarrollado e integrado en EnergyPlus para efectuar evaluaciones a escala de edificio. 

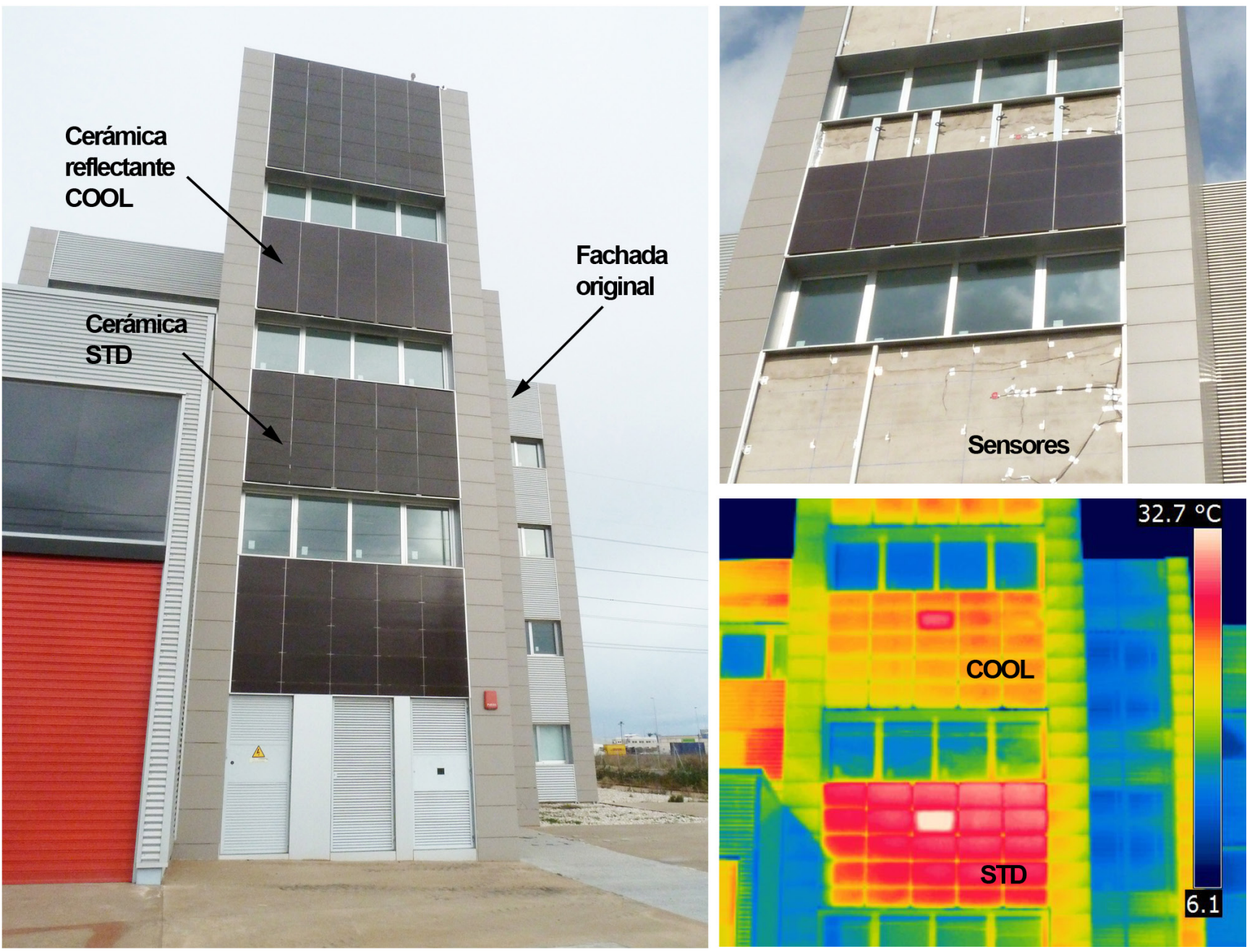

Figura 4. Vista general del edificio CIES con los dos tipos de fachada ventilada instalados (izquierda). Vista de los sensores en el interior de la fachada y termografía de ambas fachadas (derecha).

\section{SIMULACIÓN FACHADA VENTILADA REFLECTANTE EN ENERGYPLUS}

\subsection{Integración de la fachada ventilada reflectante NIR en EnergyPlus}

Aunque en la bibliografía se reconoce el ahorro energético de diferentes tipologías de cerramientos ventilados, no se dispone de estudios que validen las estimaciones efectuadas por estos programas de simulación respecto a edificios reales con fachada ventilada. Las herramientas reconocidas LIDER y CALENER, siendo válidas a efectos normativos, solamente contemplan soluciones constructivas estándar, y para evaluar nuevos elementos constructivos resulta necesario realizar simplificaciones, como el caso de la fachada ventilada que en LIDER se asimila de forma incorrecta a una resistencia térmica equivalente. Por su mayor versatilidad, el programa EnergyPlus es uno de los programas más extensamente utilizados en la actualidad, e incluso dispone de un módulo para cavidades ventiladas por tiro natural. No obstante, este modelo trata de una manera demasiado simplificada algunos de los fenómenos de transferencia térmica que tienen lugar en el sistema de fachada ventilada (9).

Por ello, partiendo de la formulación matemática de la transferencia de energía definida en EnergyPlus, se abordó el de- sarrollo de un modelo matemático completo para la simulación de la fachada ventilada reflectante.

El flujo de calor a través de la pared interior del cerramiento depende del intercambio de calor en la fachada ventilada y se puede calcular como resultado de los siguientes balances de energía:

- Balance en la pared de la fachada ventilada, donde se consideran las siguientes contribuciones: el intercambio de calor por radiación reflejada en la región de longitud de onda larga (cielo, sus alrededores y la masa vegetal), el intercambio de calor por radiación en la región de longitud de onda corta por la radiación incidente y la radiación con la hoja interna. Además del intercambio de calor por convección con el aire exterior y con el aire en el interior del canal, y la conducción a través de la pieza.

- Balance en el aire que circula en el interior del canal de la fachada ventilada con las siguientes contribuciones: flujo de entalpía del aire en el interior del canal (el cual depende del balance de energía mecánica con el que se calcula su caudal), intercambio de calor por convección con la pieza cerámica de la fachada e intercambio de calor por convección con la pared.

- Balance energético en la hoja interna de la fachada ventilada en contacto con el canal ventilado: conducción a su través, convección con el aire canal y radiación con la hoja externa. 


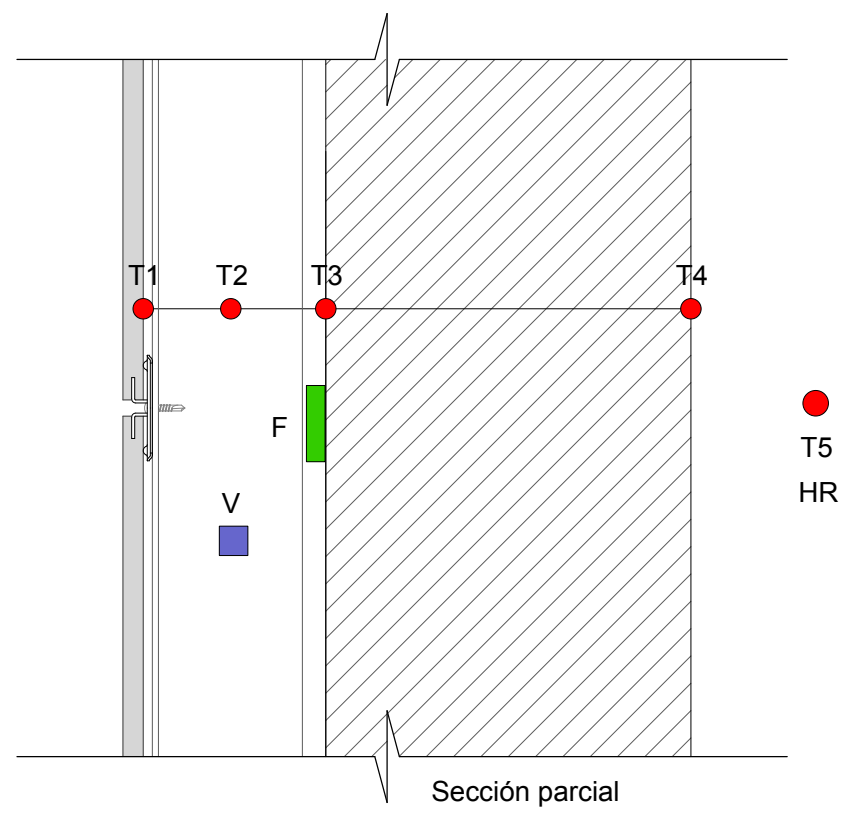
nos de transferencia con objeto de permitir una estimación precisa de la contribución térmica de este cerramiento. Para su integración en EnergyPlus se desarrolló una interfaz genérica de comunicación programada en Fortran (el mismo lenguaje de programación en el que está escrito EnergyPlus), que el programa reconoce como un módulo adicional a los que tiene disponibles. Mediante esta estrategia de comunicación, en el futuro será posible integrar también nuevos desarrollos de soluciones constructivas innovadoras para su evaluación a escala edificio.

\subsection{Validación del módulo de fachada ventilada reflectante}

Para la validación del módulo se realizaron simulaciones del edificio CIES Living Lab con EnergyPlus, y los resultados de las mismas se compararon con los datos experimentales obtenidos durante la monitorización del edificio.

\subsubsection{Modelización del edificio CIES en Energy Plus}

Para el desarrollo del modelo se agruparon los espacios interiores del edifico en diferentes zonas térmicas, en función de

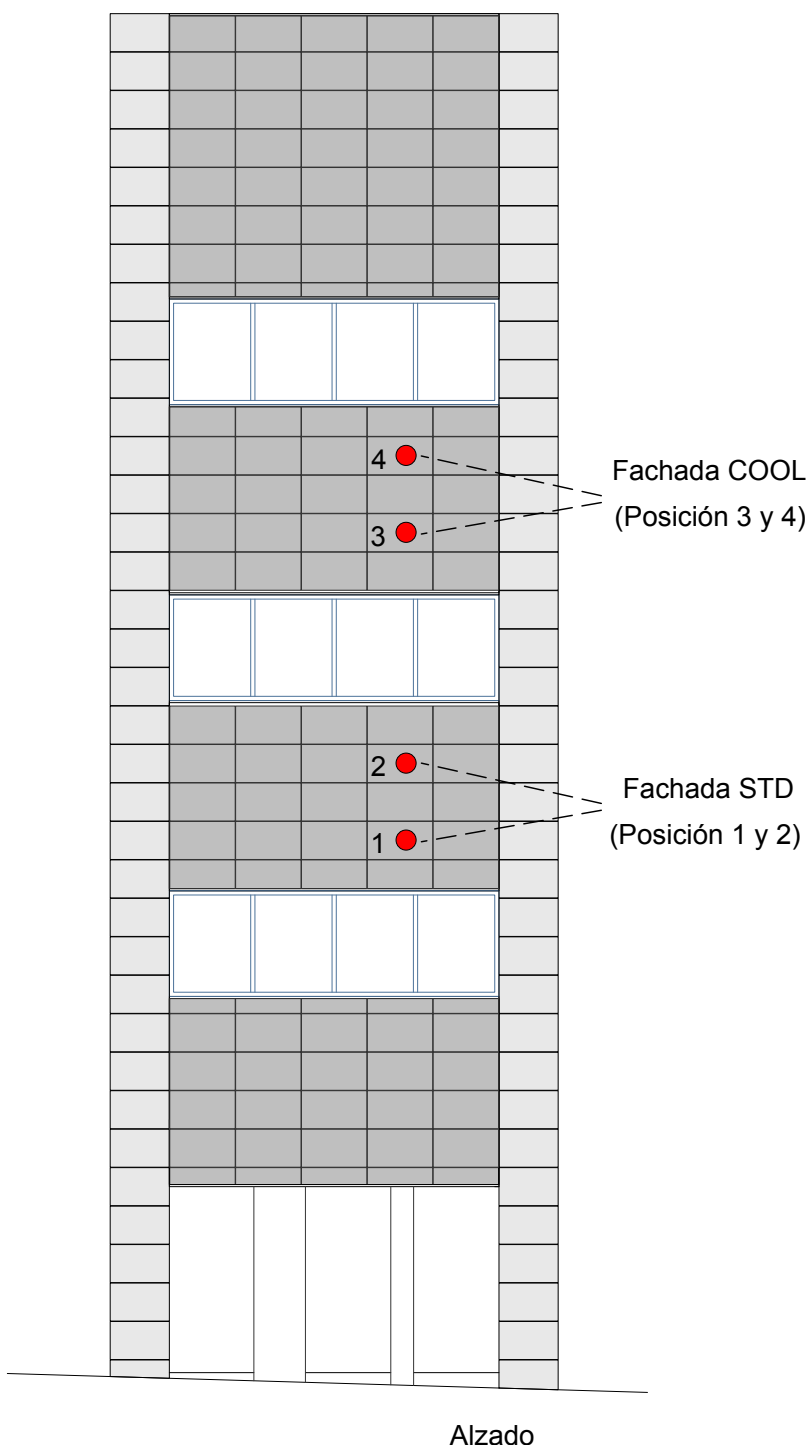

Alzado

Figura 5. Esquema de localización de la instrumentación utilizada (izquierda). Alzado edificio con identificación de las fachadas COOL y STD monitorizadas (derecha).

su orientación y altura, con el objetivo de evaluar de forma independiente aquellas zonas térmicas en las cuales se había instalado la fachada ventilada reflectante (zona térmica 1 en Figura 8) y de los que se disponía de registros reales de las distintas variables. Para modelizar el edificio se empleó el programa Open Studio a través de un plugin integrado en el programa Sketchup, incorporando las soluciones constructivas del edificio CIES.

\subsubsection{Simulación de la fachada ventilada reflectante en el edificio CIES}

Tras modelizar el edificio CIES en EnergyPlus se procedió a la simulación de la evolución diaria de las variables utilizando el módulo desarrollado para fachadas ventiladas reflectantes.

Para ello se generó un archivo de datos climáticos utilizando los valores experimentales de las condiciones ambientales registradas en el edificio para diferentes días a lo largo del periodo anual. Dado que el programa EnergyPlus no considera de forma efectiva la información disponible relativa a la dirección de incidencia del viento, para efectuar la comparación con los datos experimentales de evolución de las variables del cerramiento, se decidió seleccionar aquellas que 


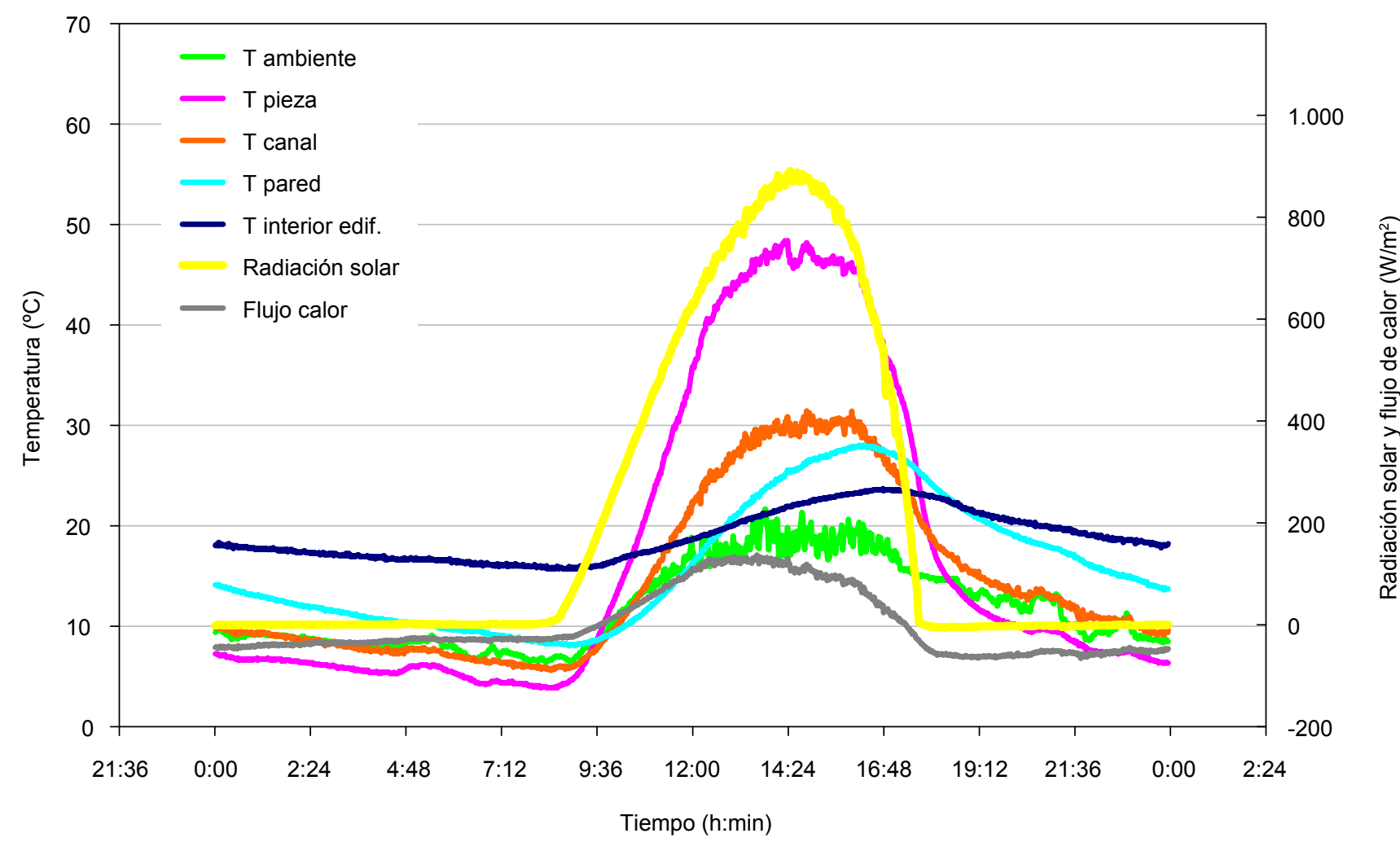

Figura 6. Registro diario de las variables monitorizadas en el canal ventilado con baldosas STD en el edificio CIES el 8 de enero.

manifestaban un menor dependencia de las fluctuaciones en la dirección del viento (temperatura de pieza, temperatura y flujo de calor en el muro).

Finalmente se realizaron simulaciones para diferentes días de los periodos de invierno, primavera y verano, y se comparó la evolución real de las variables de referencia respecto a los valores estimados mediante el modelo matemático desarrollado. La validación se efectuó considerando tanto los resultados de la fachada ventilada convencional (STD) como de la fachada ventilada reflectante (COOL).

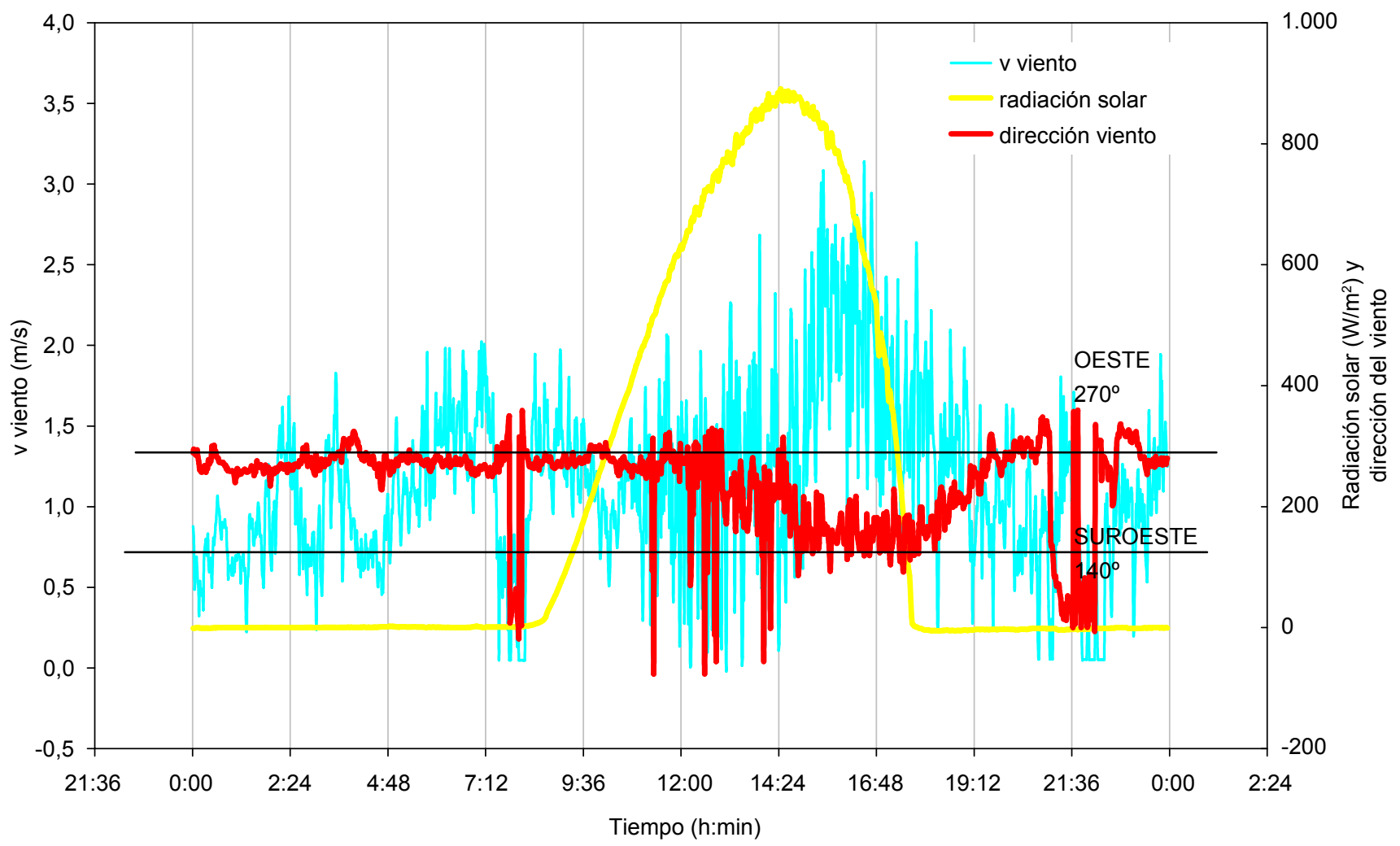

Figura 7. Registro diario de las condiciones ambientales externas en el edificio CIES el 8 de enero. 


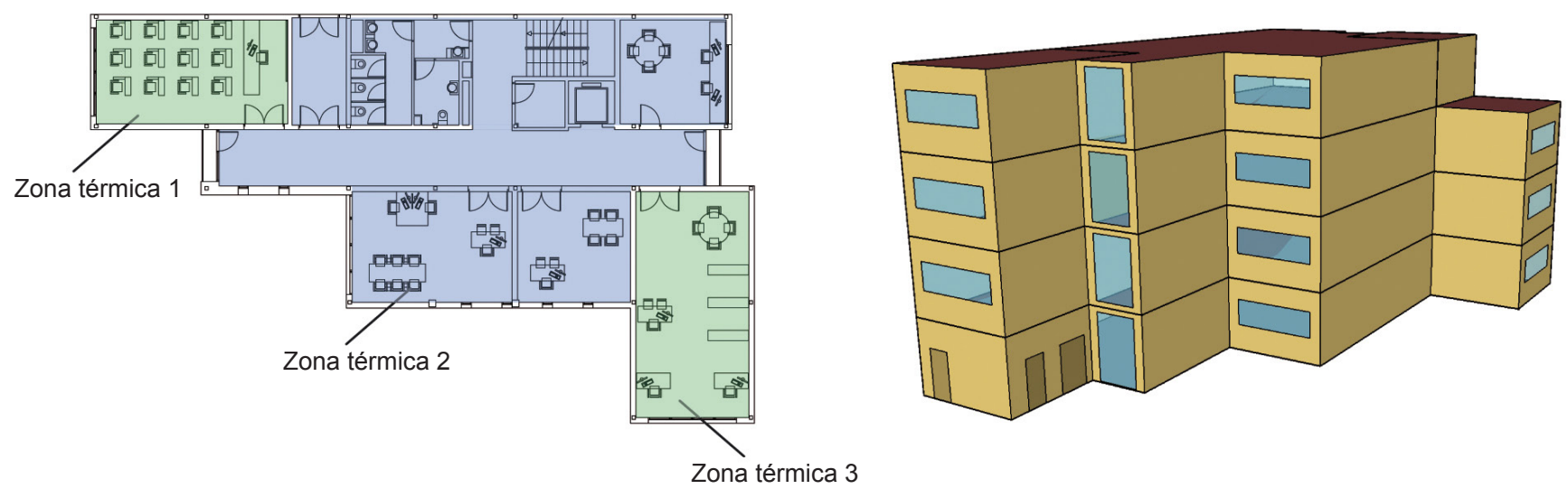

Figura 8. Esquema planta edificio CIES (izquierda) y edificio CIES modelizado (derecha).

En la Figura 9 se han representado un ejemplo de los datos obtenidos en un día de invierno con alta radiación solar. Se presentan conjuntamente los resultados teóricos (líneas gruesas) con los datos experimentales (líneas finas) para ambos tipos de fachadas. Como puede comprobarse los valores obtenidos con el modelo matemático implementado en EnergyPlus reproducen fielmente la evolución de los valores experimentales registrados durante la fase de monitorización del edificio.

En la Figura 10 se presentan los resultados para un día soleado de verano, en el que análogamente se confirma la precisión del modelo de simulación desarrollado para las condiciones climáticas opuestas.

Asimismo se compararon las magnitudes de los flujos de calor experimentales respecto a los obtenidos mediante el programa de simulación. En las Figura 11 y Figura 12 se presenta la comparación de los resultados de la transmisión de energía a través del muro para un día de verano y de invierno, respectivamente. Como puede observarse la ganancia térmica en el caso de la fachada ventilada con pieza cerámica convencional es superior a la que se alcanza con la baldosa cerámica reflectante en el NIR. En ambas condiciones de intensidad de radiación solar la evolución del flujo de calor simulado durante la fase de radiación solar se ajusta correctamente a los datos experimentales, aunque estos últimos presentan una mayor oscilación derivada de las fluctuaciones instantáneas de la radiación solar, las cuales solamente pueden introducirse en el fichero de datos climáticos con resolución horaria.

En base a estos resultados se concluyó que el modelo matemático desarrollado permitía simular fielmente el comportamiento de la fachada ventilada reflectante y, por lo tanto, su adecuación para efectuar estimaciones en diferentes tipologías de edificios y condiciones climáticas.

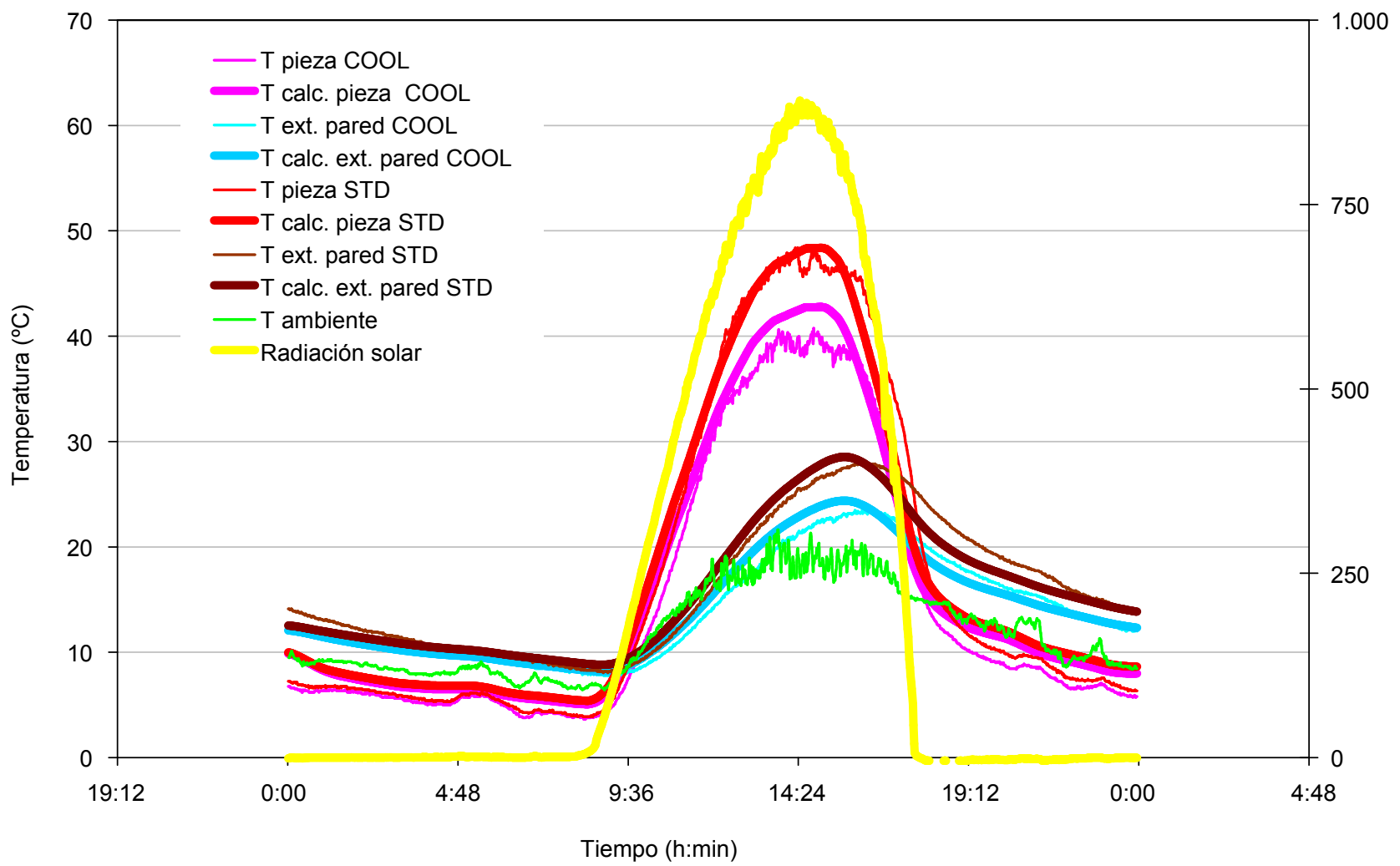

Figura 9. Validación de las temperaturas simuladas frente a los datos experimentales monitorizados para un día de invierno (8 de enero). 


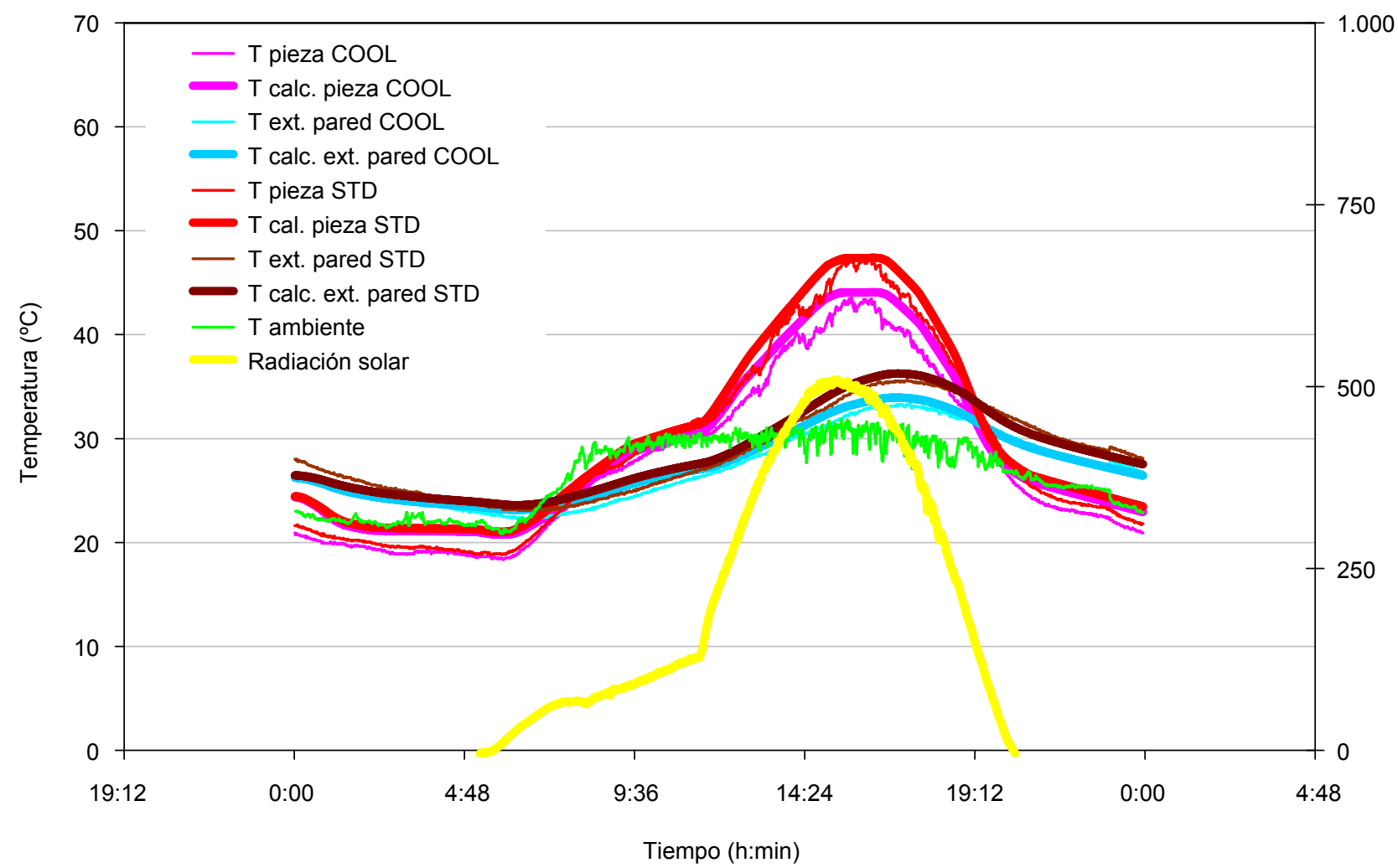

Figura 10. Validación de las temperaturas simuladas frente a los datos experimentales monitorizados para un día de verano (20 de junio).

\section{EVALUACIÓN ENERGÉTICA DE LA REHABILITACIÓN MEDIANTE FACHADA VENTILADA CERÁMICA REFLECTANTE}

Una vez validada la herramienta informática para la simulación del comportamiento térmico de la fachada ventilada con piezas cerámicas reflectantes en el NIR, se abordó el análisis de su contribución a la reducción de la demanda energética en la rehabilitación de edificios.

Las simulaciones desarrolladas para uso residencial y terciario se han realizado sobre un edificio con tipología de bloque, con dos fachadas exteriores con un porcentaje medio de huecos del $20 \%$ y otras dos entre medianeras (que se han considerado adiabáticas para la simulación). El edificio tipo está formado por planta baja y seis plantas sobre rasante, con un núcleo central de comunicación y dos estancias laterales por planta (Figura 13). Las características de los elementos constructivos originales se han asociado a las habituales en los edificios construidos en la década de los 8o, según se detalla en la Tabla 1. Se ha considerado que los materiales empleados en cubierta y fachada tienen una absortancia de 0,7 y una emisividad de o,82. Las transmitancias térmicas de estos cerramientos son las siguientes: fachada $\left(1,33 \mathrm{~W} / \mathrm{m}^{2} \mathrm{~K}\right)$, cubierta $\left(1,92 \mathrm{~W} / \mathrm{m}^{2} \mathrm{~K}\right)$ y vidrios $\left(3,3 \mathrm{~W} / \mathrm{m}^{2} \mathrm{~K}\right)$.

Las cargas internas del edificio tipo, tanto para residencial como para terciario (ocupación, luminarias, equipos), se establecieron de acuerdo a las especificaciones del documento «condiciones de aceptación de procedimientos alternativos a LIDER y CALENER» (10).

Para la rehabilitación del edificio tipo se ha considerado la instalación de un sistema de fachada ventilada con aisla- miento por el exterior y baldosas cerámicas reflectantes, de absortancia solar 0,60 y emisividad o,82.

Respecto al aislamiento se ha considerado un material aislante con conductividad de $0,032 \mathrm{~W} / \mathrm{mK}$ y se ha tomado como valor medio de aislamiento $60 \mathrm{~mm}$ de espesor, en base a las exigencias de transmitancia mínima definidas para la zona climática $\mathrm{B}_{3}\left(\mathrm{U}=0,38 \mathrm{~W} / \mathrm{m}^{2} \mathrm{~K}\right)$ en el «Apéndice E. Valores orientativos de los parámetros característicos de la envolvente térmica» del DBHE del CTE.

Para las condiciones de uso residencial se han efectuado simulaciones considerando dos tipos de orientaciones de las fachadas exteriores (Norte-Sur y Este-Oeste) y para tres tipos de climas (A4, B3 y E1). Para poder analizar las causas del ahorro energético se han representado conjuntamente las demandas anuales de calefacción y refrigeración del edificio original sin rehabilitar (referenciado como «Fachada años 80») y del edificio rehabilitado con fachada cerámica reflectante (referenciado como «FV COOL (ais. $60 \mathrm{~mm} »$ ). Los resultados obtenidos se presentan en la Figura 14.

Como se observa en la Figura 15, la incorporación del cerramiento ventilado reflectante en un edificio de uso residencial produce una reducción tanto de la demanda de calefacción como la demanda de refrigeración, independientemente de la orientación y de la zona climática considerada en España. En la zona climática cálida (A4) la mejora energética deriva principalmente de la reducción en la demanda de refrigeración y está asociada a la limitación de las ganancias térmicas a través del cerramiento en el periodo estival, mientras que la zona más fría (E1) el ahorro, que se manifiesta principalmente en la demanda de calefacción, se asocia a la incorporación del aislante que reduce las pérdidas en invierno. Para con- 


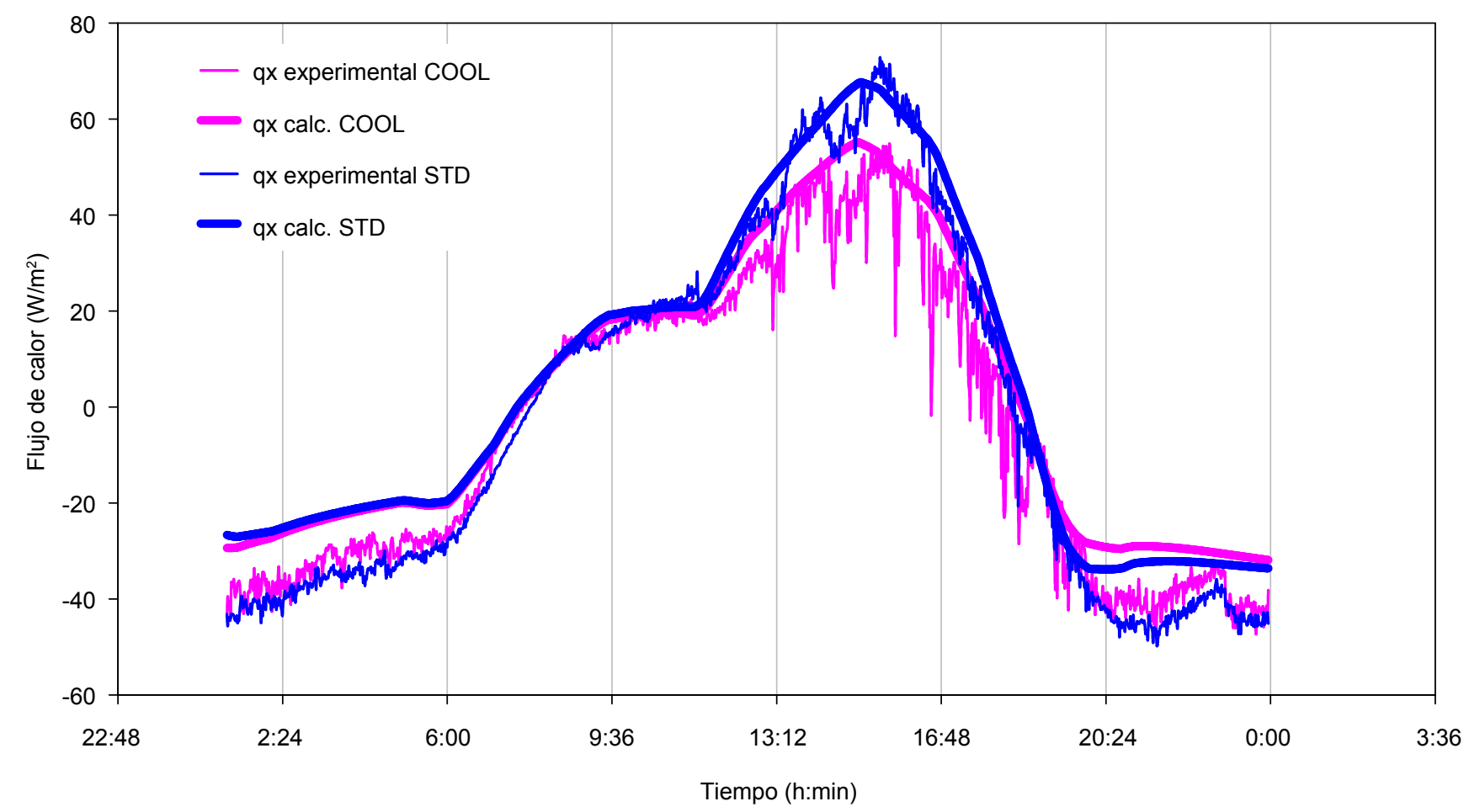

Figura 11. Validación de los flujos de calor simulados frente a los datos experimentales monitorizados para un día de verano (20 de junio).

diciones climáticas intermedias (B3) ambos factores parecen tener contribuciones similares (Tabla 2).

Cabe resaltar que las mejoras relacionadas con la demanda de refrigeración son algo superiores en la orientación EsteOeste, debido a que el ángulo de incidencia de la radiación solar es más perpendicular en el periodo estival para estas orientaciones, mientras que la reducción de la demanda de calefacción parece independiente de la orientación, confirmando que en este caso depende principalmente de la mejora de la resistencia térmica del cerramiento.

Para las simulaciones de un edificio terciario se han considerado unas cargas internas para un uso terciario de intensidad media (12 horas), siendo un caso intermedio entre las opciones definidas en el «anexo III. Condiciones operacionales»

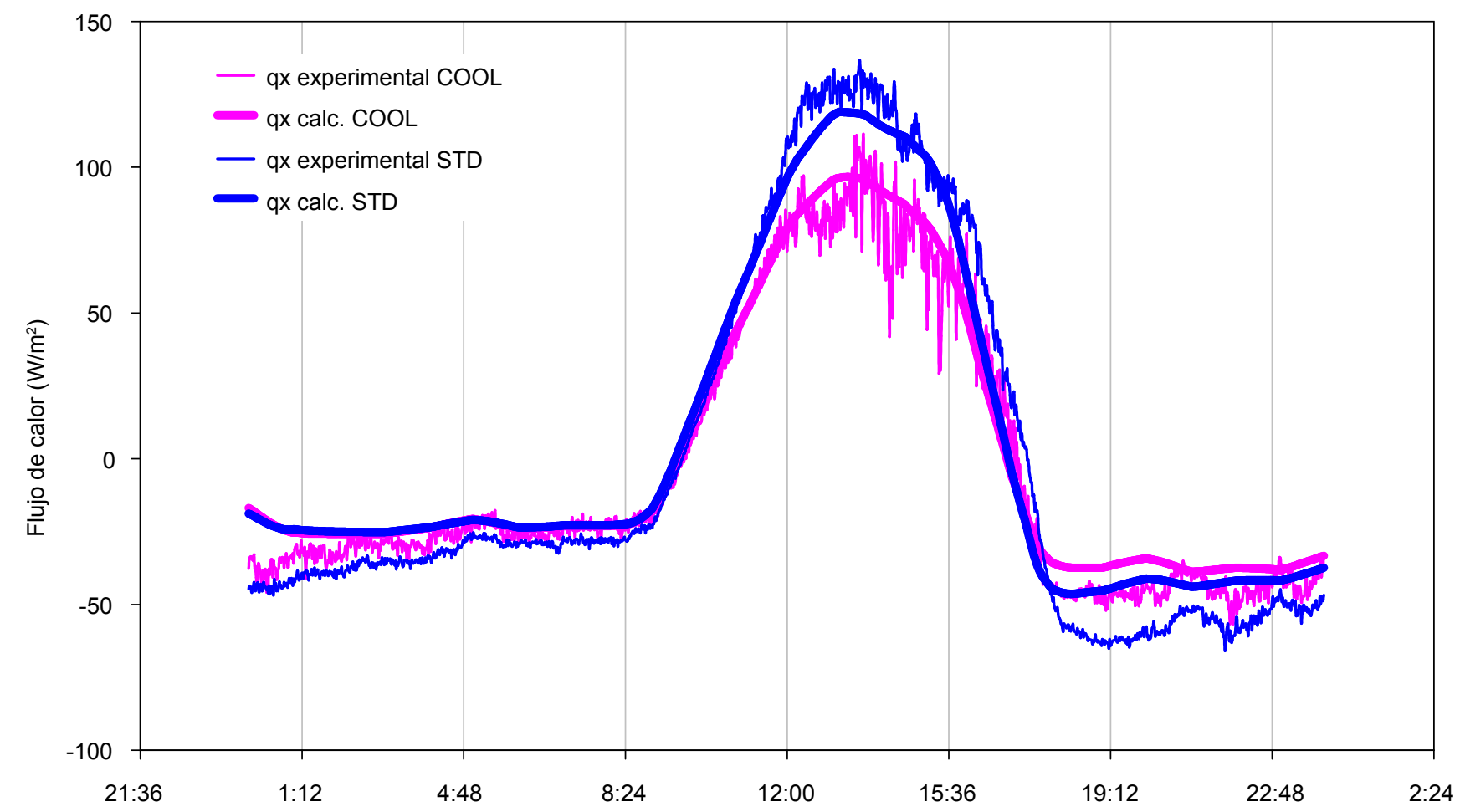

Figura 12. Validación de los flujos de calor simulados frente a los datos experimentales monitorizados para un día de invierno (8 de enero). 

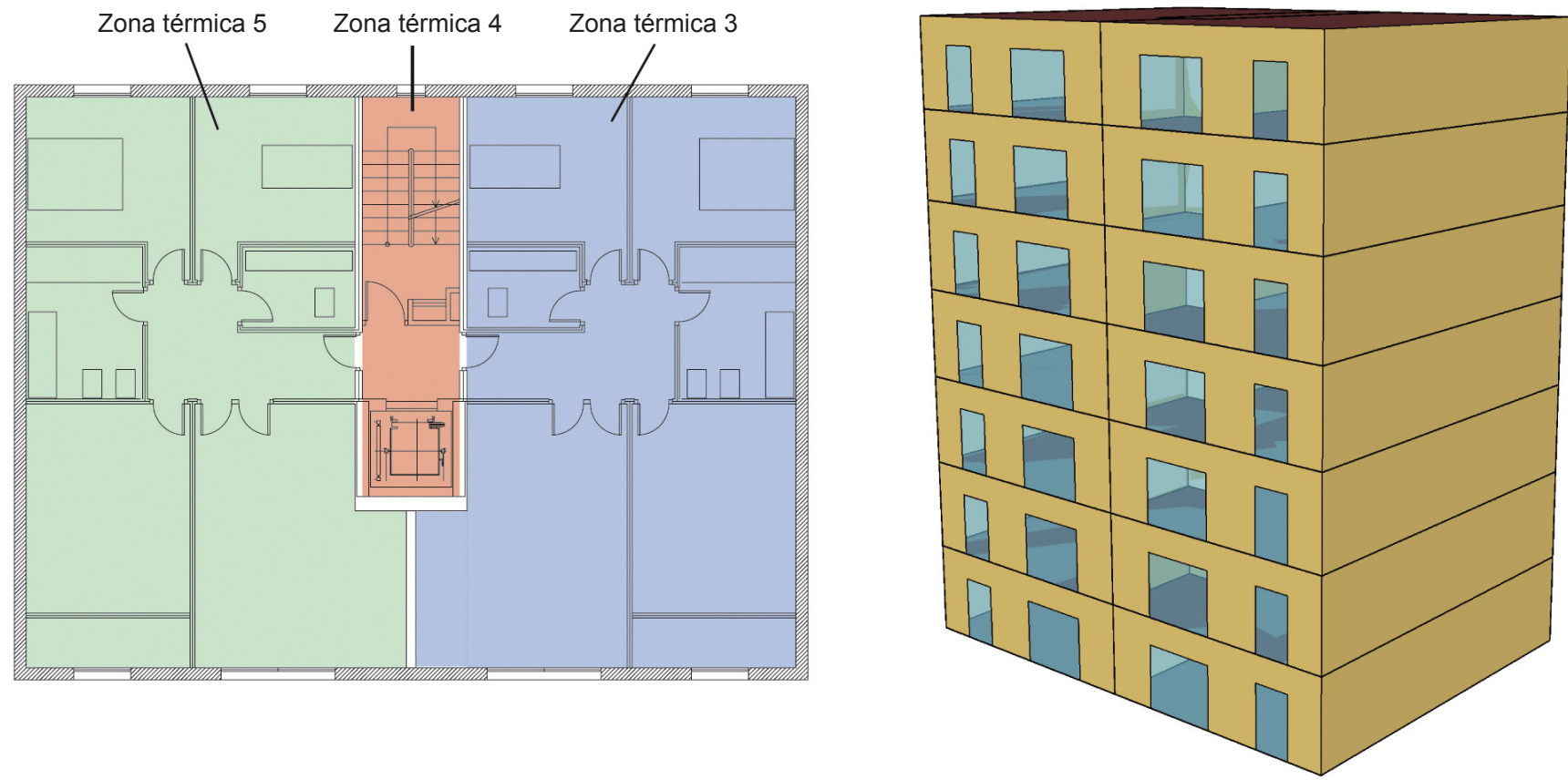

Figura 13. Esquema en planta y vista 3D del edificio tipo modelado.

Tabla 1. Propiedades de los cerramientos del edificio de los años 80 .

\begin{tabular}{|c|c|c|c|c|c|}
\hline & Material & $\begin{array}{l}\text { Espesor } \\
(\mathrm{m})\end{array}$ & $\begin{array}{c}\text { Conductividad } \\
(\mathrm{W} / \mathrm{mK})\end{array}$ & $\begin{array}{c}\text { Densidad } \\
\left(\mathrm{kg} / \mathrm{m}^{3}\right)\end{array}$ & $\begin{array}{c}\text { Calor específico } \\
\text { (J/kgK) }\end{array}$ \\
\hline \multirow{5}{*}{ Fachada } & Capa 1. Enfoscado mortero de cemento & 0,015 & 0,55 & 1.125 & 1.000 \\
\hline & Capa 2. Ladrillo cerámico hueco doble & 0,115 & 0,427 & 920 & 1.000 \\
\hline & Capa 3. Cámara de aire vertical & 0,05 & \multicolumn{3}{|c|}{$\mathrm{o}, 18 \mathrm{o} \mathrm{m}^{2} \mathrm{~K} / \mathrm{W}$ (resistencia térmica) } \\
\hline & Capa 4. Ladrillo cerámico hueco simple & 0,04 & 0,445 & 1.000 & 1.000 \\
\hline & Capa 5. Enlucido de yeso & 0,01 & 0,570 & 1.150 & 1.000 \\
\hline \multirow{5}{*}{ Cubierta } & Capa 1. Baldosa cerámica & 0,015 & 1 & 2.000 & 800 \\
\hline & Capa 2. Mortero de cemento & 0,055 & 0,55 & 1.125 & 1.000 \\
\hline & Capa 3. Lámina de betún & 0,005 & 0,230 & 1.100 & 1.000 \\
\hline & Capa 4. FU entrevigado de hormigón & 0,25 & 1,323 & 1.330 & 1.000 \\
\hline & Capa 5. Enlucido de yeso & 0,01 & 0,4 & 900 & 1.000 \\
\hline
\end{tabular}

(10). Los resultados obtenidos en la simulación del edificio terciario con fachadas orientadas Este-Oeste para las tres zonas climáticas se muestran en la Figura 15.

Para su análisis debe tenerse en cuenta que estos edificios se caracterizan por tener elevadas cargas internas (ocupación, iluminación, equipos, etc.), así como por una elevada tasa de renovación con aire exterior. Por esta razón las demandas de refrigeración son mucho más elevadas que las de calefacción, y solamente de orden similar en zonas climáticas frías (E1).

Para estas condiciones de uso la rehabilitación con una capa de aislamiento de $60 \mathrm{~mm}$ apenas modifica las demandas de refrigeración del edificio, y los ahorros obtenidos se deben casi exclusivamente a la reducción de la demanda de calefacción en el periodo invernal. Este efecto es probablemente debido a que las ganancias térmicas asociadas a la absorción de radiación solar son poco significativas en proporción a las derivadas de las cargas internas y de la renovación con aire externo en el periodo estival.

Para comprobarlo se han efectuado nuevas simulaciones de la rehabilitación del edificio con un espesor inferior de ais- lamiento (40 mm, según se recomienda para la zona A4) y con fachada ventilada sin incorporación de aislante (Figura 15). Si comparamos las demandas de refrigeración para los distintos niveles de aislamiento se confirma que el aumento de la resistencia térmica de cerramiento tiene un efecto negativo en la demanda, ya que imposibilita la evacuación hacia el exterior de las cargas térmicas generadas en el interior del edificio, por lo que en las zonas cálidas debería considerarse limitar la incorporación de aislamiento.

Por ello, para optimizar el consumo energético en edificios con elevadas cargas internas, sería necesario aplicar otras medidas adicionales a las de rehabilitación de la envolvente, siendo recomendable la utilización de soluciones de ventilación nocturna, al menos durante los periodos estivales, y la utilización de elementos de sombreado en los huecos.

En conclusión, la rehabilitación con fachada ventilada cerámica reflectante en edificios de uso residencial y terciarios conlleva reducciones de la demanda global en las tres zonas climáticas estudiadas (Figura 16), siendo más significativas en edificios de uso residencial. En función de las zonas climáticas y de las características del edificio se pueden obtener 
DEMANDAS EN RESIDENCIAL $\left(\mathrm{kWh} / \mathrm{m}^{2}\right)$

- CALEFACCIÓN Fachada años 80

- REFRIGERACIÓN Fachada años 80
CALEFACCIÓN FV COOL (ais. $60 \mathrm{~mm}$ )

REFRIGERACIÓN FV COOL (ais. 60 mm)

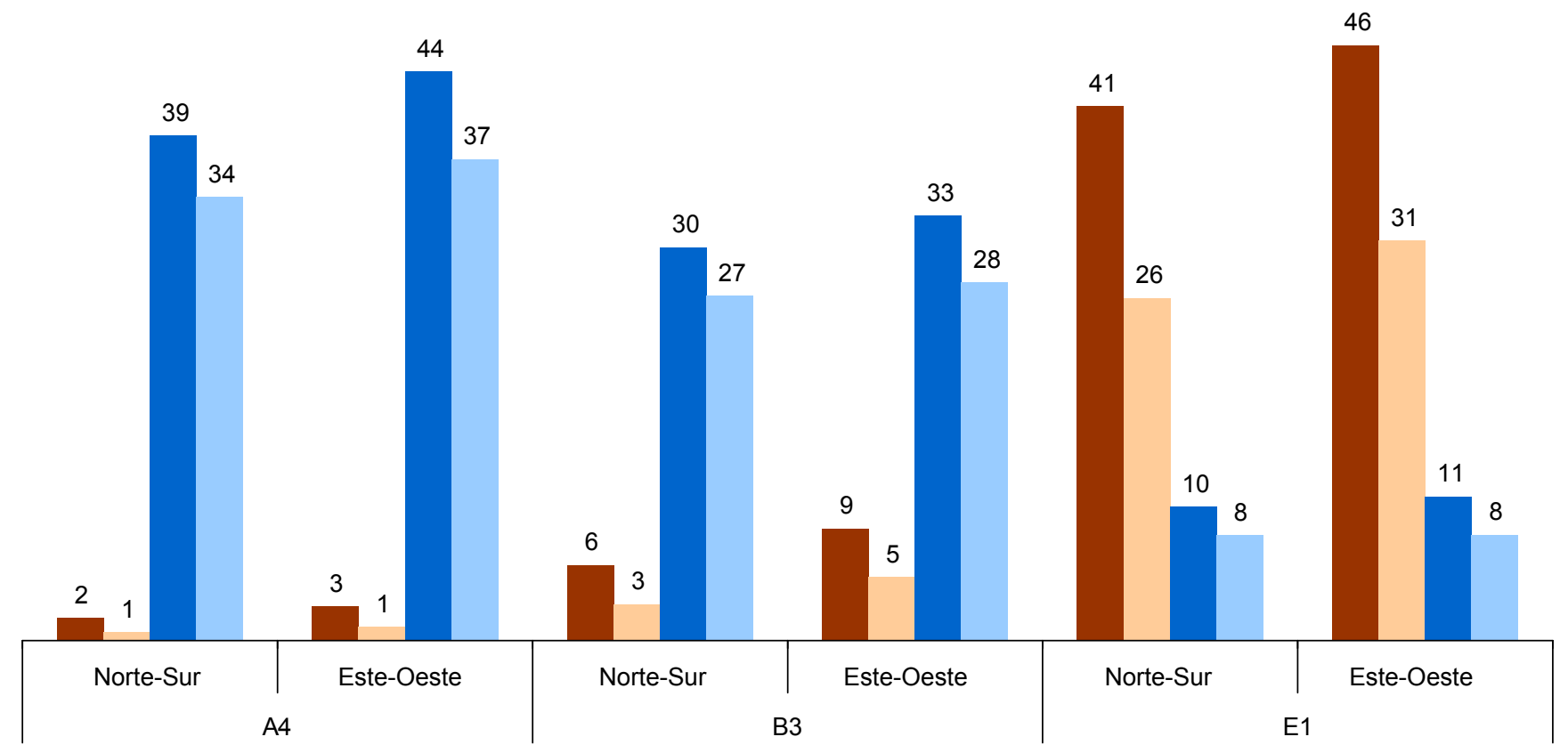

Figura 14. Comparación demandas anuales en edificio residencial años 80 y rehabilitado con fachada ventilada cerámica reflectante.

ahorros energéticos entre un 18 y un $32 \%$ en condiciones de uso residencial, y entre un 3 y un $20 \%$ para terciario en la rehabilitación con fachada ventilada COOL con un aislamiento de $60 \mathrm{~mm}$.
Los sistemas de fachada ventilada en la rehabilitación de la envolvente del edificio ofrecen además una serie de ventajas adicionales a las ya indicadas, entre las que destacan: la eliminación de puentes térmicos y condensaciones, la durabilidad

\section{DEMANDAS TERCIARIO $\left(\mathrm{KWh} / \mathrm{m}^{2}\right)$}

Fachada años $80 \quad$ FV COOL (ais. $60 \mathrm{~mm}$ ) $\quad$ FV COOL (ais. $40 \mathrm{~mm}$ ) $\quad$ FV COOL (sin ais.)

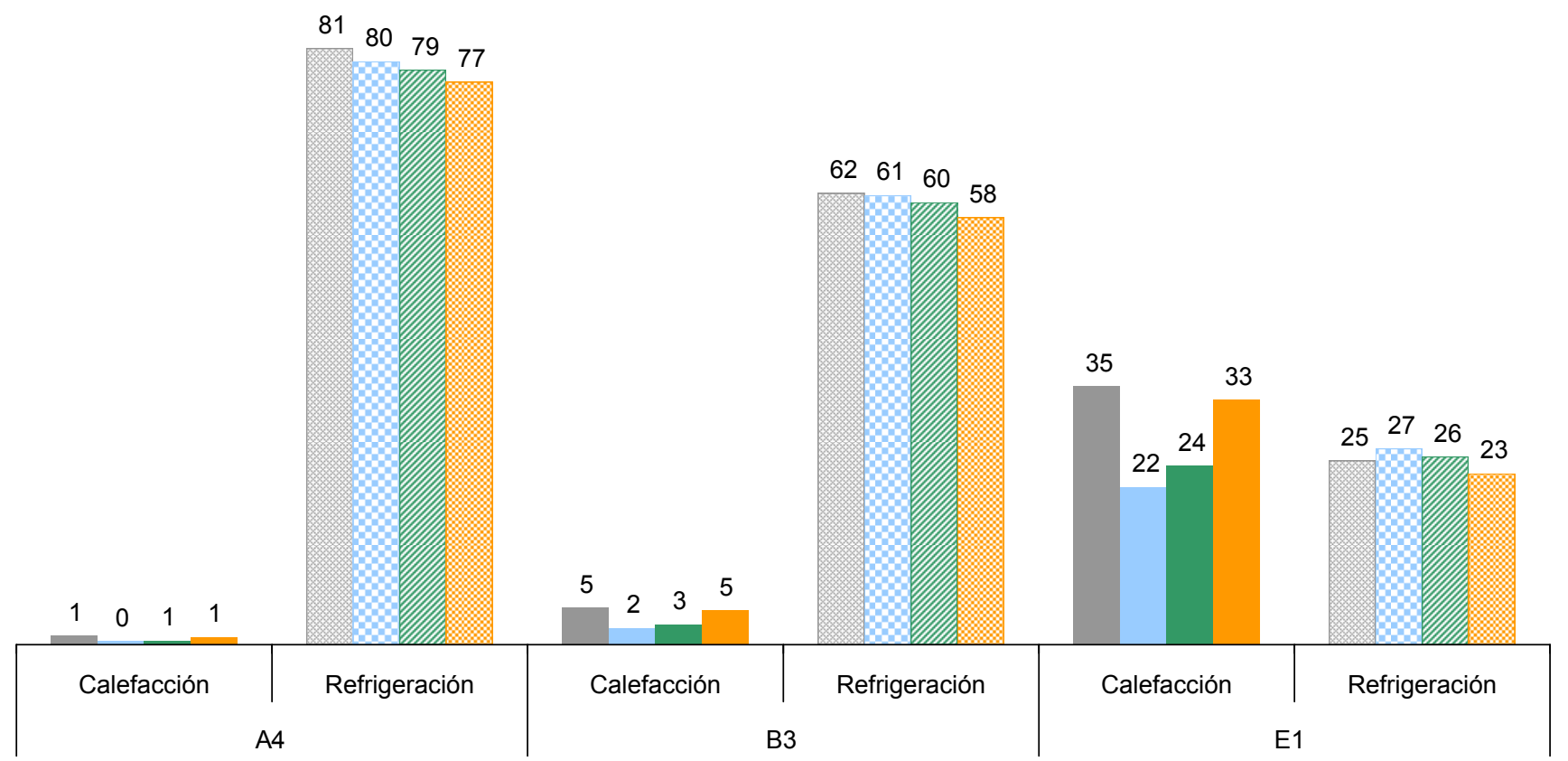

Figura 15. Comparación demandas anuales en edificio terciario años 80 y rehabilitado con fachada ventilada cerámica reflectante. Orientación Este-Oeste. 
Tabla 2. Influencia de los componentes del sistema constructivo.

\begin{tabular}{|c|c|c|c|c|}
\hline \multirow{2}{*}{\multicolumn{2}{|c|}{$\begin{array}{l}\text { Variación porcentual respecto a demanda } \\
\text { total edificio original }\end{array}$}} & \multicolumn{3}{|c|}{ Zona climática } \\
\hline & & \multirow{2}{*}{$\begin{array}{c}\mathbf{A 4}(\%) \\
-0,1\end{array}$} & \multirow{2}{*}{$\begin{array}{c}\text { B3 (\%) } \\
-0,3\end{array}$} & \multirow{2}{*}{$\begin{array}{c}\text { E1 (\%) } \\
-0,5\end{array}$} \\
\hline \multirow{5}{*}{ Calefacción } & Aplacado reflectante (sin aisl.) & & & \\
\hline & FV reflectante (sin aisl.) & 0,6 & 0,9 & 3,6 \\
\hline & Aislamiento $(3 \mathrm{~cm})$ & 2,2 & 6,8 & 22,4 \\
\hline & FV reflectante $+3 \mathrm{~cm}$ & 2,3 & 6,8 & 22,6 \\
\hline & FV reflectante $+6 \mathrm{~cm}$ & 2,7 & 8,4 & 28,7 \\
\hline \multirow{5}{*}{ Refrigeración } & Aplacado reflectante (sin aisl.) & 3,0 & 3,2 & 1,7 \\
\hline & FV reflectante (sin aisl.) & 9,5 & 9,4 & 4,6 \\
\hline & Aislamiento $(3 \mathrm{~cm})$ & 5,9 & 5,1 & 1,9 \\
\hline & FV reflectante $+3 \mathrm{~cm}$ & 11,5 & 10,6 & 4,7 \\
\hline & FV reflectante $+6 \mathrm{~cm}$ & 11,6 & 10,3 & 4,3 \\
\hline \multirow{5}{*}{ Total } & Aplacado reflectante (sin aisl.) & 2,9 & 2,9 & 1,2 \\
\hline & FV reflectante (sin aisl.) & 10,1 & 10,3 & 8,2 \\
\hline & Aislamiento $(3 \mathrm{~cm})$ & 8,1 & 11,9 & 24,3 \\
\hline & FV reflectante $+3 \mathrm{~cm}$ & 13,8 & 17,4 & 27,3 \\
\hline & FV reflectante $+6 \mathrm{~cm}$ & 14,3 & 18,7 & 33,0 \\
\hline
\end{tabular}

REDUCCIÓN DEMANDA GLOBAL (\%)

FV COOLTerciario $\quad$ FV COOL Residencial

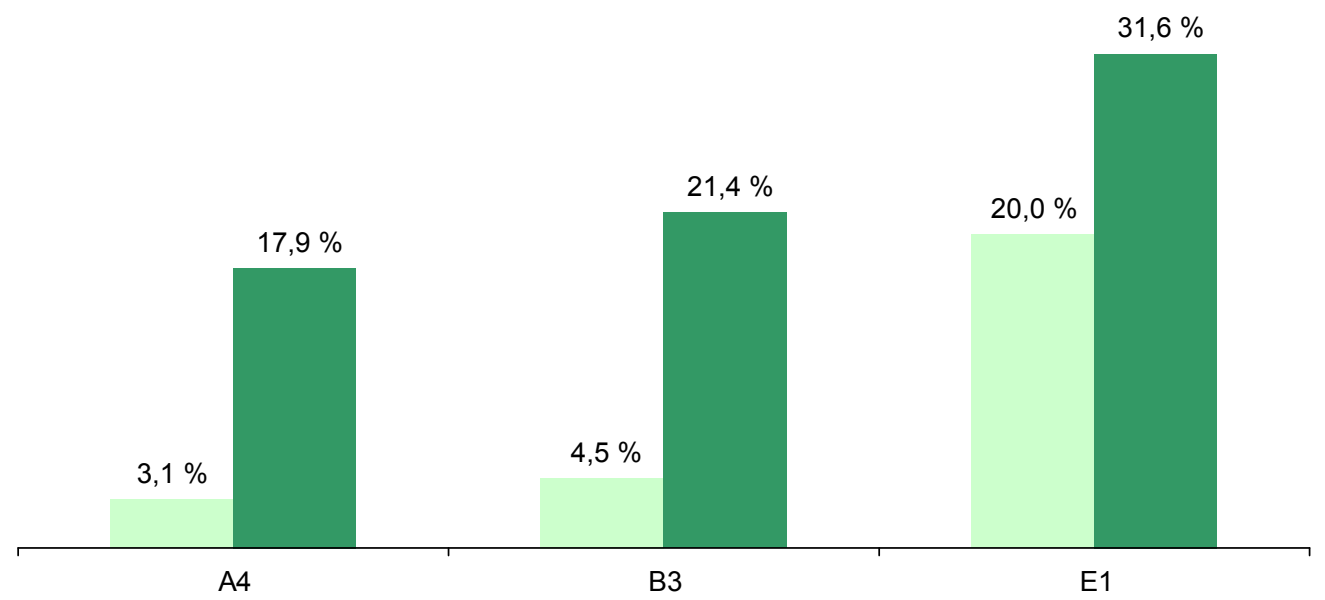

Figura 16. Ahorros energéticos en demanda global al rehabilitar con FV COOL en edificio de uso residencial y terciario con aislante $60 \mathrm{~mm}$, Este-Oeste.

frente a agentes externos, el bajo coste de mantenimiento durante los 50 años de su vida útil, la comodidad para el usuario al realizar la instalación del sistema por el exterior, evitando la reducción de las dimensiones de los espacios interiores.

Además de estas prestaciones funcionales, la fachada ventilada tiene un alto potencial estético, al ofrecer versatilidad en cuanto al diseño y la personalización tanto del producto como del aspecto formal de la envolvente, aportando valor añadido a la fachada y revalorizando el inmueble.

\section{AGRADECIMIENTOS}

Este estudio ha sido cofinanciado por la plataforma ClimateKIC en el marco del proyecto Building Technologies Accelerator (BTA).

\section{REFERENCIAS}

(1) Tumini, I. (2010, 30 de abril). Estrategias para reducción del efecto isla de calor en los espacios urbanos. Estudio aplicado al caso de Madrid. En Ponencia SB1O MAd, Edificación sostenible, Revitalización y Rehabilitación de Barrios. Madrid, España.

(2) Alchapar, N., Correa, E. (2015). Reflectancia solar de las envolventes opacas de la ciudad y su efecto sobre las temperaturas urbanas. Informes de la Construcción, 67(540): e112 ,doi: http://dx.doi.org/10.3989/ic.14.131 
(3) Suárez, C., Molina, J.L. (2015). Análisis del efecto chimenea en fachadas ventiladas opacas mediante correlaciones del flujo másico inducido. Aplicación para el dimensionado de anchos de cámara. Informes de la Construcción, 67(538): eo87, doi: http://dx.doi.org/10.3989/ic.13.155.

(4) Silva, G., Cantavella, V., García, À.R., Bou, E., Miralles, A., Uviedo, E. (2010, 15 de febrero). Estudio de la eficiencia energética de fachadas ventiladas cerámicas. En Qualicer'1o Foro global del recubrimiento cerámico. Castellón, España.

(5) Bannier, E., Cantavella, V., Silva, G., Pinazo, J.M., Soto, V.M., Sarabia, E. (2012, 13 de febrero). Contribución de la fachada ventilada a la demanda energética de un edificio. En Qualicer'12 Foro global del recubrimiento cerámico. Castellón, España.

(6) COOL-Coverings. (2013 October). Project: Development of a novel and cost-effective range of nanotech improved coatings to substantially improve NIR (Near Infrared) properties of the building envelope, co-financed by the EU commission under FP7 (CA 260132). http://cordis.europa.eu/project/rcn/94644_en.html.

(7) Revel, G.M., Martarelli, M., Bengochea, M.A., Gozalbo, A., Orts, M.J., Gaki, A., Gregou, M., Taxiarchou, M., Bianchin, A., Emiliani, M. (2013). Nanobased coatings with improved NIR reflecting properties for building envelope materials: Development and natural aging effect measurement. Cement \& Concrete Composites, 36: 128-135.

(8) Revel, G.M., Martarelli, M., Emiliani, M., Gozalbo, A., Orts, M.J., Bengochea, M.A. (2014). Cool products for building envelope - Part I: Development and lab scale testing, Solar Energy, 105: 770-779, doi: http://dx.doi.org/10.1016/j. solener.2014.03.029.

(9) Soto, V.M., Sarabia, E.J., Pinazo, J.M., Bannier, E., Cantavella, V., Silva, G. (2013). Modeling of ventilated façades for energy building simulation software. Energy and Buildings, 65: 419-428, doi: http://dx.doi.org/10.1016/j. enbuild.2013.06.015.

(10) Condiciones de aceptación de procedimiento alternativos a LIDER y CALENER. Instituto para la Diversificación y Ahorro de la Energía (IDAE). Madrid, mayo 2009. 